\title{
Influence of bisphosphonates on the adherence and metabolism of epithelial cells and gingival fibroblasts to titanium surfaces
}

\author{
Fernanda Gonçalves Basso ${ }^{1,2,3}$ • Taisa N. Pansani ${ }^{1,3}$ • Diana G. Soares ${ }^{1,3} \cdot$ Lais M. Cardoso $^{1,3}$ • \\ Josimeri Hebling ${ }^{1,3} \cdot$ Carlos Alberto de Souza Costa ${ }^{1,3}$
}

Received: 13 March 2017 / Accepted: 23 June 2017 / Published online: 8 July 2017

(C) Springer-Verlag GmbH Germany 2017

\begin{abstract}
Objectives To evaluate the effects of sodium alendronate (SA) and zoledronic acid (ZA), on the adhesion and metabolism of epithelial cells and gingival fibroblasts to titanium surfaces considering cell functions related to an effective mucosal barrier around the implant.

Materials and methods Cells were seeded onto titanium discs and incubated for $24 \mathrm{~h}$. Then, serum-free DMEM containing selected bisphosphonates $(0,0.5,1$, or $5 \mu \mathrm{M})$ was added for 24 and $48 \mathrm{~h}$. Factors related to the achievement of an effective mechanical and immunological barrier - cell adhesion, viability, collagen epidermal growth factor, and immunoglobulin synthesis - were evaluated. Data were analyzed by Kruskal-Wallis and Mann-Whitney tests as well as by ANOVA and Tukey's tests, $(\alpha=0.05)$

Results The presence of bisphosphonates culminated in lower cell adhesion to the titanium discs, particularly for SA at $5 \mu \mathrm{M}$ (40\%) and ZA at all concentrations (from 30 to 50\%, according to increased concentrations). Reduced cell viability occurred after exposing these cells to ZA (40\%); however, only $5 \mu \mathrm{M}$ SAtreated cells had decreased viability $(30 \%)$. Reduced synthesis of growth factors and collagen was observed when cells were
\end{abstract}

Fernanda Gonçalves Basso

fergbasso@gmail.com

1 Araraquara School of Dentistry, Universidade Estadual Paulista UNESP, Araraquara, SP, Brazil

2 Department of Physiology and Pathology, School of Dentistry, Araraquara, São Paulo State University (Unesp), Araraquara, SP, Brazil

3 Araraquara School of Dentistry, Campus Araraquara, São Paulo State University (Unesp), Araraquara, SP, Brazil reated with ZA ( 20 and $40 \%$, respectively), while about $70 \%$ of IgG synthesis was enhanced.

Conclusion Bisphosphonates negatively affected the adhesion and metabolism of oral mucosal cells, and this effect was related to the type of bisphosphonate as well as to concentration and period of treatment.

Clinical relevance The negative effects of bisphosphonates on oral mucosal cells can hamper the formation of an effective biological seal in osseointegrated implants.

Keywords Fibroblast · Implantology $\cdot$ Bisphosphonate · Connective tissue biology

\section{Introduction}

After intake, bisphosphonates show highly selective affinity for mineralized tissues, especially for hydroxyapatite crystals (1), and the release of these drugs can be triggered by physiological bone remodeling or by inflammatory events, leading to pathological resorption (2). Once released from these tissues, the cellular effects of drugs show poor specificity (3-6). As a main effect, bisphosphonates inhibit the maturation of pre-osteoclasts into osteoclasts and also induce the apoptosis of these cells, preventing bone loss (7-9). Secondary cellular effects, however, have been extensively described, such as high toxicity to osteoblasts, fibroblasts, and epithelial cells $(3-6,10-14)$, and these events have been associated with the development of bisphosphonate-related osteonecrosis of the jaws (BRONJ) (15, 16).

Some studies have assessed the local and systemic factors related to the development of this condition $(7,15,17,18)$. Administration route and potency (type of bisphosphonate) have been described as the main factors associated with these adverse effects $(2,15)$. Previous studies have also demonstrated that these 
factors are related to the toxicity of these drugs to several cell types (3-6, 10-14).

Due to these events, the insertion of oral osseointegrated implants into patients undergoing bisphosphonate treatment is controversial (19-21). This controversy is based on the development of BRONJ lesions in patients receiving ongoing bisphosphonate therapy, as well as to the failure of oral implant treatment in these patients (19-22).

The success of oral implants is related primarily to bone formation and biological sealing (23); therefore, local or systemic factors can interfere with the integration of these components into the bone tissue (osteointegration) or with the adhesion of oral mucosa, thus contributing to implant failure.

Therefore, the achievement of high-quality biological sealing by the adhesion of oral mucosal cells to implant surfaces is crucial for the maintenance of these prosthetic components, since it provides a physical and immunological barrier, preventing bacterial invasion and also providing esthetics for these components (23).

Since reports in the literature have already demonstrated the toxicity of bisphosphonates to oral mucosal cells, the failure of implant therapy in patients under bisphosphonate treatment may be due to a direct toxic effect of these drugs $(5,6$, $12,13)$. However, the fact that not all patients receiving bisphosphonate therapy show negative outcomes for oral implants (19-22) suggests that these failures can also be related to the types and regimens of bisphosphonates.

Therefore, this study evaluated the effects of two bisphosphonates, sodium alendronate (SA) and zoledronic acid (ZA), on the adhesion and metabolism of epithelial cells and gingival fibroblasts to titanium surfaces.

\section{Material and methods}

\section{Disc preparation}

Commercially pure titanium discs (grade IV, $13 \times 1.5 \mathrm{~mm}$ ) were obtained and ground wet with 400-, 600-, and 1200-grit silicon carbide paper (3 M do Brasil, Sumaré, SP, Brazil) to obtain standardized surfaces. Surface roughness was evaluated by means of a confocal microscope (ULS 4000, Olympus Corporation, Center Valley, PA, USA). Then, discs were ultrasonically cleaned in $95 \%$ ethanol and deionized water and were sterilized in an autoclave.

\section{Cell culture}

Human epithelial cells (HaCaT - CLS 300493) were cultured in Dulbecco's Modified Eagle Medium (DMEM, Gibco, Carlsbad, CA, USA), containing antibiotic Pen/Strep solution (1\%, Gibco) and $10 \%$ fetal bovine serum (FBS, Gibco) in a humidified incubator $\left(37^{\circ} \mathrm{C}, 5 \% \mathrm{CO}_{2}\right)$. Gingival fibroblasts were isolated from a healthy young individual during a tooth extraction procedure, according to a protocol approved by the university's Ethics Committee (CAAE: 1432113.7.0000.5416). For cell isolation, gingival tissue was subjected to enzymatic digestion for $24 \mathrm{~h}$, with collagenase type I ( $3 \mathrm{mg} / \mathrm{mL}$; Worthington Biochemical Corp., Lakewood, NJ, USA) in serum-free culture medium containing antibiotic/antimycotic solution $(1 \%$, Gibco) in a humidified incubator $\left(37{ }^{\circ} \mathrm{C}, 5 \% \mathrm{CO}_{2}\right)$ (Thermo Fisher Scientific, Waltham, MA, USA).

For the experimental procedures, titanium discs were placed at the bottoms of wells of 24-well plates. Then, $1 \mathrm{~mL}$ of culture medium was added to each well, and epithelial cells or gingival fibroblasts were seeded onto the discs $\left(1 \times 10^{5}\right.$ cells/disc) and incubated for $24 \mathrm{~h}$.

\section{Bisphosphonates}

Twenty-four hours after being seeded, the culture medium was replaced by serum-free DMEM containing different concentrations of sodium alendronate (SA) or zoledronic acid (ZA) $(0.5,1$, or $5 \mu \mathrm{M})$ (Sigma-Aldrich, St. Louis, MO, USA). The drugs were maintained in contact with cells for 24 or $48 \mathrm{~h}$.

\section{Cell adhesion}

The adhesion of epithelial cells and fibroblasts after treatment with SA or ZA was evaluated by scanning electron microscopy (SEM). Samples were processed according to standard protocol previously reported and were maintained in a desiccator for 7 days, covered with gold, and analyzed by scanning electron microscopy (Inspect Scanning Electron Microscope S50; FEI, Hillsboro, OR, USA) (5).

\section{Expression of cell adhesion molecules H-CAM and actin and determination of adherent cell number}

The adhesion of epithelial cells was also qualitatively evaluated by the expression of cell adhesion molecules (H-CAM/CD44), while the adhesion and cytoskeletal conformation of fibroblasts were analyzed by the expression of actin by immunofluorescence. Cells were fixed in $4 \%$ formalin for $24 \mathrm{~h}$ at $4{ }^{\circ} \mathrm{C}$. Then, these samples were washed three times in cold PBS (5 min each) and were incubated with $3 \%$ bovine serum albumin (BSA) solution for $1 \mathrm{~h}$, then washed with PBS. Primary antibodies for CD44 (mouse anti-CD44, $100 \mu \mathrm{g} / \mathrm{mL}$ in 3\% BSA; Santa Cruz Biotechnology Inc., Dallas, TX, USA) or anti-actin conjugated with Alexa Fluor 630 nm (1:100, Molecular Probes, Carlsbad, CA, USA) was added to each sample and incubated for $1 \mathrm{~h}$. Epithelial cells were also stained with secondary antibody (goat anti-mouse IgG [Molecular Probes], conjugated with AlexaFluor $488 \mathrm{~nm}-1: 100$ in 1\% BSA) for $2 \mathrm{~h}$. A DNA intercalator (Hoechst, 1:5000 - Molecular Probes) was used to identify cells. Positive fluorescence was detected by an inverted fluorescence 
microscope (EVOS FL Image System, Thermo Fisher Scientific).

The number of cells that remained attached to the titanium surface after treatment with SA and ZA at different concentrations was determined by fluorescence microscopy by nuclei staining with the DNA intercalator (Hoechst, 1:5000 Molecular Probes). Four photomicrographs of each sample were obtained, and these images were analyzed with ImageJ software (Wayne Rasband, National Institutes of Health, Bethesda, MD, USA).

\section{Cell viability}

The viability of cultured cells was evaluated by the MTT assay (14). To each sample, a solution of DMEM containing $10 \%$ of MTT salt ( $5 \mathrm{mg} / \mathrm{mL}$ in phosphate buffer) was added. Cells were incubated for $4 \mathrm{~h}$ in a humidified incubator $\left(37^{\circ} \mathrm{C}, 5 \%\right.$ $\mathrm{CO}_{2}$ ). During this period, the enzyme succinic dehydrogenase of viable cells promoted the cleavage of MTT salt, resulting in the formation of purple formazan crystals. These crystals were then dissolved in acidified isopropanol. An aliquot of $200 \mu \mathrm{L}$ of each sample was transferred to a 96-well plate, and absorbance of each sample was evaluated by spectrophotometry ( 570 nm; Synergy H1, Bio Tek, Winooski, VT, USA). The viability of each sample was determined according to the mean absorbance of the control group (100\% viability).

\section{Collagen synthesis}

Total collagen secreted by gingival fibroblasts was determined by the Sirius Red method. Briefly, an aliquot $(400 \mu \mathrm{L})$ of the culture medium that remained in contact with cells was added to an equal volume of $0.1 \%$ direct red solution (SigmaAldrich) in saturated picric acid. Samples were incubated for $1 \mathrm{~h}$ under agitation (400 rpm, Thermomixer - Eppendorf, Hamburg, Germany) and centrifuged at 10,000 rpm for 10 min (Microcentrifugal 5415R, Eppendorf). Then, supernatant was discarded, and samples were washed with hypochlorous acid $(0.1 \mathrm{M})$ followed by centrifugation $(10,000 \mathrm{rpm} / 10 \mathrm{~min})$. The total collagen pellet was resuspended in sodium hydroxide $(0.5 \mathrm{M})$. An aliquot of $200 \mu \mathrm{L}$ of each sample was transferred to a 96-well plate and then subjected to absorbance determination (562 nm, Synergy H1, Bio Tek).

\section{EGF and VEGF synthesis}

Synthesis of epidermal growth factor (EGF) by epithelial cells and vascular endothelial growth factor (VEGF) by gingival fibroblasts was assessed by the enzyme-linked immunosorbent assay (ELISA), with standardized kits (DuoSet, R\&D Systems, Minneapolis, MN, USA), in accordance with the manufacturer's instructions. Briefly, aliquots of culture medium in contact with cells during treatment were stored at $-20^{\circ} \mathrm{C}$ until analysis. Then, plates were prepared by overnight incubation with primary antibodies $(1 \mu \mathrm{g} / \mathrm{mL})$ at room temperature. Plates were washed three times with $1 \%$ washing solution and treated with Reagent Diluent solution (BSA) for $1 \mathrm{~h}$. Samples and standard curve aliquots $(100 \mu \mathrm{L})$ were added to the plates and incubated for $2 \mathrm{~h}$, followed by washing and incubation with secondary antibodies $(100 \mathrm{ng} / \mathrm{mL})$ for an additional $2 \mathrm{~h}$.

As a next step, plates were subjected to washing and incubation with a $100-\mu \mathrm{L}$ quantity of $1: 40$ streptavidin solution for $20 \mathrm{~min}$, followed by washing, incubation with reagent solution, and stop solution. Then, the absorbance of each sample was read in a spectrophotometer at $455 \mathrm{~nm}$ (Synergy H1, Bio Tek). The concentration of this growth factor for each sample was determined according to a standard curve containing known EGF or VEGF concentrations.

\section{Synthesis of IgG}

Synthesis of immunoglobulin G by epithelial cells was detected by ELISA assay (R\&D Systems), according to protocol described above.

\section{Statistical analysis}

Data on cell adhesion, cell viability, synthesis of collagen, EGF, and VEGF were analyzed by Kruskal-Wallis and Mann-Whitney tests, while results of IgG synthesis were analyzed by ANOVA and Tukey's tests $(\alpha=0.05)$.

\section{Results}

\section{Cell adhesion by SEM}

Results demonstrated that treatment of epithelial cells and gingival fibroblasts with bisphosphonates led to significant morphological alterations in these cells, especially for zoledronic acid (Fig. 1a, b). Further, images revealed a significant impact on the adhesion of these cells to titanium surfaces after the addition of bisphosphonates, and this effect seemed to increase over time.

\section{Expression of cell adhesion molecules}

The expression of HCAM by epithelial cells was selected for qualitative demonstration of the adhesion and spreading of these cells onto the titanium surfaces. The results showed that, for SA, decreased cell adhesion was observed starting at $5 \mu \mathrm{M}$, while for $\mathrm{ZA}$, similar results were detected for lower concentrations, starting at $0.5 \mu \mathrm{M}$ (Fig. 2a), for both periods, but with more intense effects at $48 \mathrm{~h}$. Adhesion of gingival fibroblasts was also qualitatively assessed by the immuno-identification of actin filaments, which demonstrated results similar to those for epithelial 


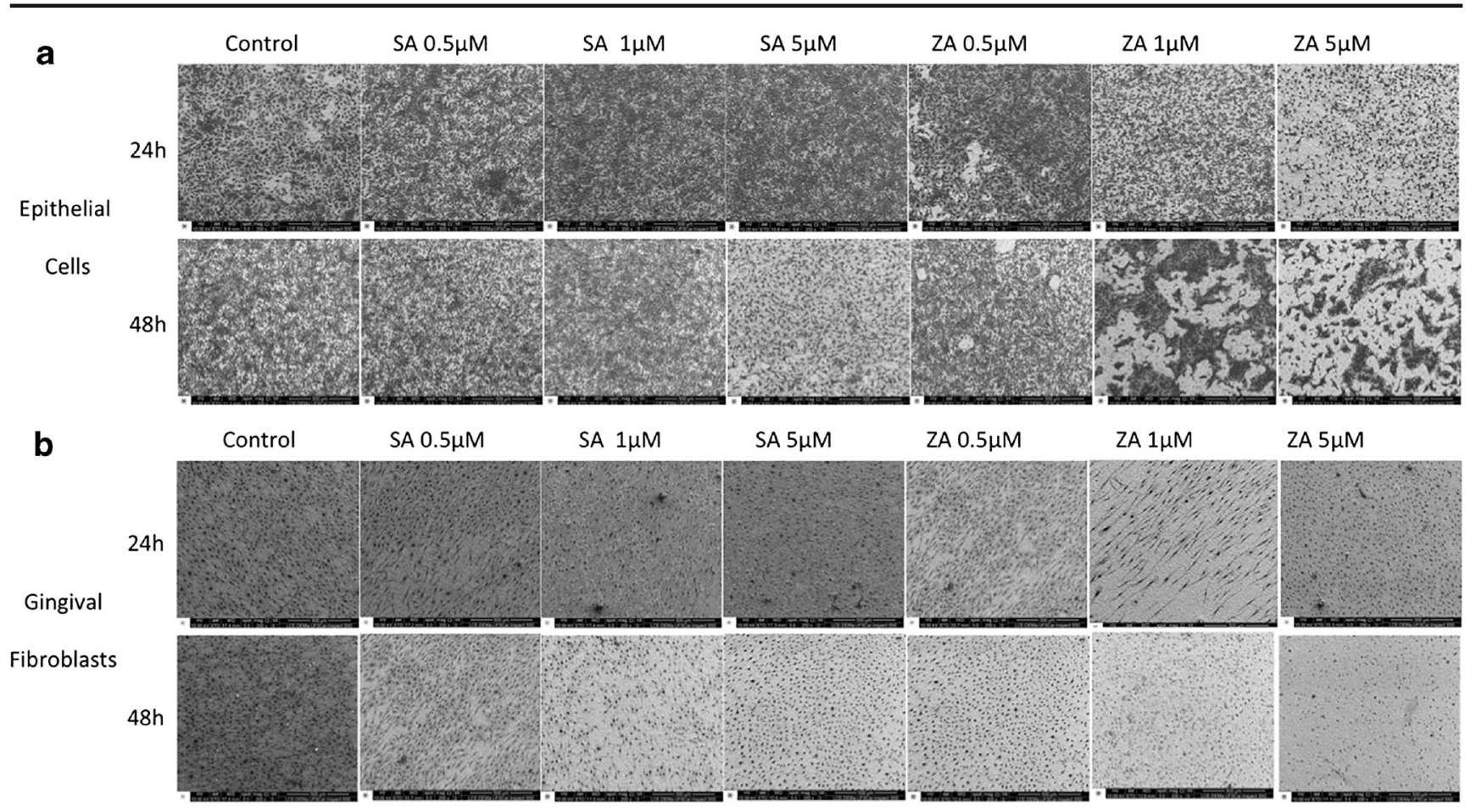

Fig. 1 Morphology of epithelial cells (a) and gingival fibroblasts (b) adhered to titanium surfaces and treated with sodium alendronate (SA) and zoledronic acid (ZA) at different concentrations for 24 and $48 \mathrm{~h}$. Scanning electron microscopy (SEM), $\times 200$

cells, with extensive cell damage for ZA-treated fibroblasts, but also decreased adhesion of SA-treated cells, especially for $5 \mu \mathrm{M}$ (Fig. 2a). Gingival fibroblasts seemed to be more negatively affected by bisphosphonates when compared with the epithelial cells. For both cell lines, effects were concentration- and timedependent (Fig. 2b).

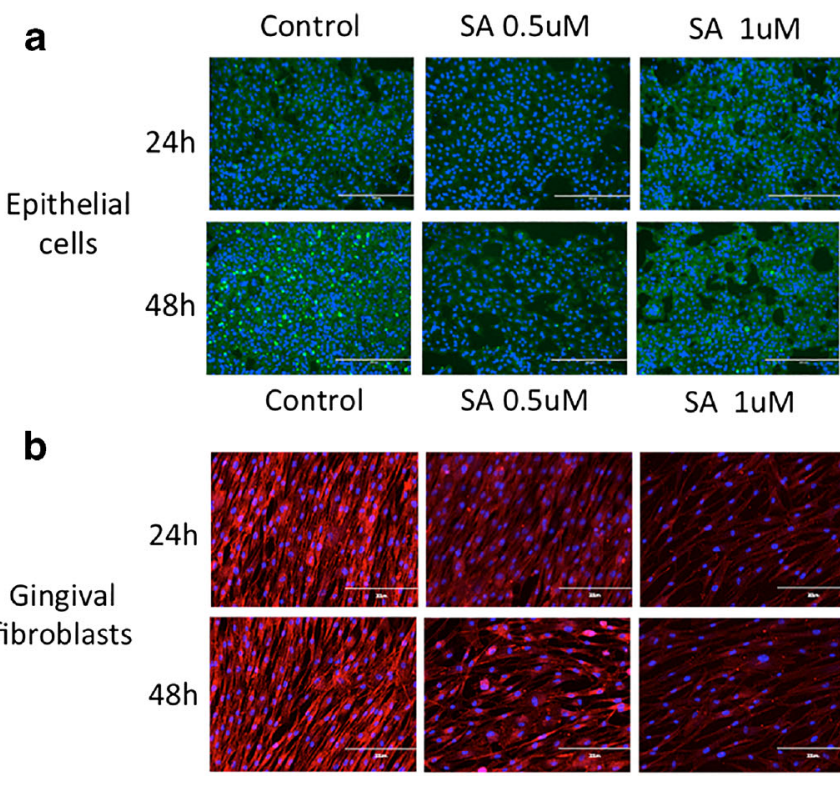

Fig. 2 Photomicrographs of membrane expression of HCAM (green) by epithelial cells adhered to titanium surfaces and treated with ZA or SA for 24 or $48 \mathrm{~h}$ (a). Nuclei were stained with Hoescht $(\times 10)$;

\section{Cell number}

Quantitative analysis of the number of cells that remained attached to the titanium substrate after bisphosphonate treatment revealed that, for epithelial cells, there was a significant decrease in the number of cells that remained attached to the

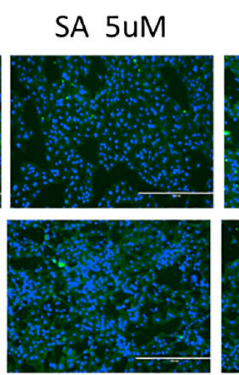

SA 5uM
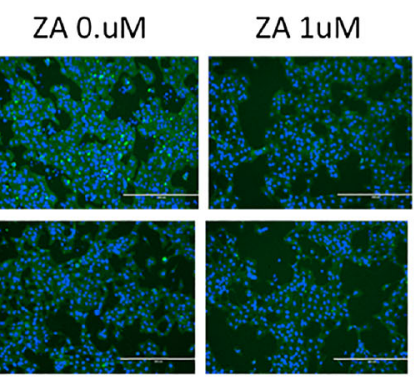

ZA 1 UM
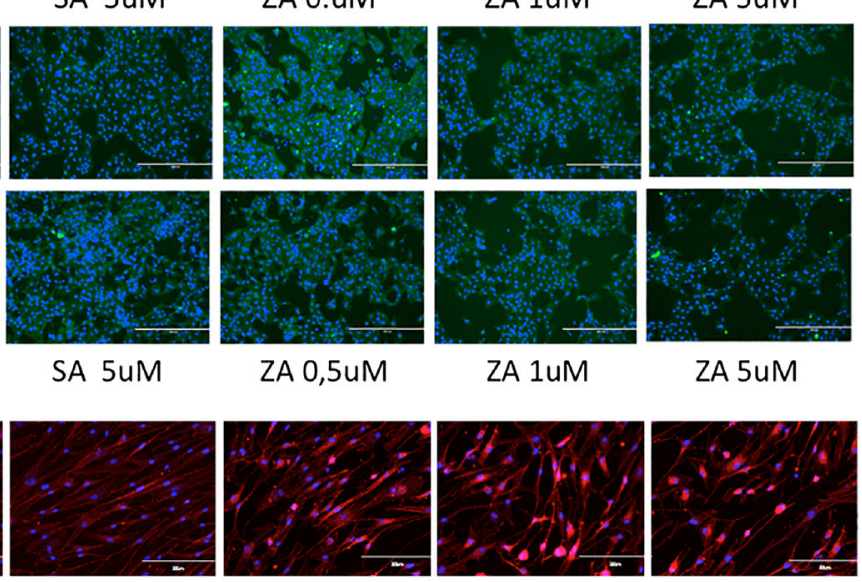

ZA 0,5 UM
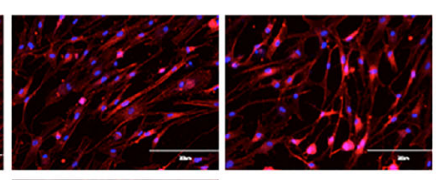

ZA 5uM
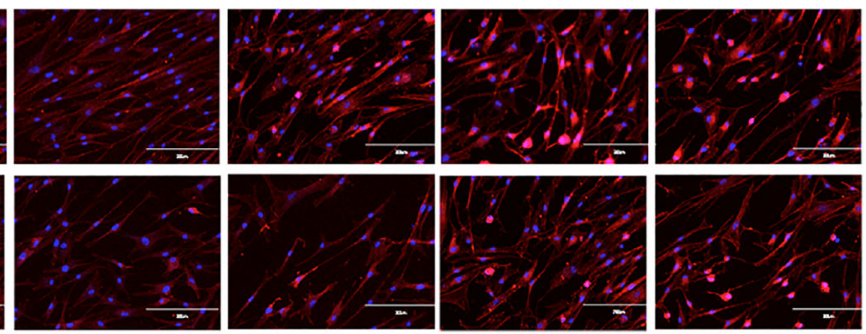

Photomicrographs of cytoskeletal identification of actin (red) of gingival fibroblasts adhered to titanium surfaces and treated with ZA or SA for 24 or $48 \mathrm{~h}(\mathbf{b})$. Nuclei were stained with Hoescht $(\times 10)$ 
discs for cells treated with SA at $5 \mu \mathrm{M}$ and with ZA at all concentrations (Figs. 2 a and $3 \mathrm{a}$ ). At $48 \mathrm{~h}$, both bisphosphonates at all concentrations decreased the number of cells adhering to the substrate (Figs. $2 \mathrm{~b}$ and $3 \mathrm{~b}$ ).

At $24 \mathrm{~h}$, only groups of gingival fibroblasts treated with SA and $\mathrm{ZA}$ at $5 \mu \mathrm{M}$ demonstrated a decrease in the number of cells attached to the titanium discs (Figs. 2c and 3c). All experimental groups demonstrated decreased numbers of gingival fibroblasts attached to titanium surfaces after $48 \mathrm{~h}$ of contact with bisphosphonates (Figs. $2 \mathrm{~d}$ and $3 \mathrm{~d}$ ).

\section{Cell viability}

Treatment of epithelial cells with SA and ZA for $24 \mathrm{~h}$ had no significant effect on the viability of epithelial cells, except for ZA at $5 \mu \mathrm{M}$ (Fig. 4a). At 48 h, however, both bisphosphonates at all concentrations promoted a significant decrease in the viability of these cells (Fig. 4b).

For gingival fibroblasts, after $24 \mathrm{~h}$ of contact with the bisphosphonates, only the groups treated with $\mathrm{ZA}$ at the three selected concentrations showed reduced cell viability, while cells treated with SA demonstrated viability similar to that of the control group (Fig. 4c). At 48 h, a similar result was observed; however, the group treated with SA at $5 \mu \mathrm{M}$ also showed decreased cell viability, similar to that caused by ZA treatment (Fig. 4d).

\section{Collagen synthesis}

Collagen synthesis by epithelial cells was not affected by bisphosphonate treatment for $24 \mathrm{~h}$; however, at $48 \mathrm{~h}$, decreased synthesis of this protein was observed when cells were exposed to ZA at 1 and $5 \mu \mathrm{M}$ (Fig. 5a). For gingival fibroblasts, this synthesis was not affected by bisphosphonates at both periods of analysis (Fig. 5b). Results of collagen synthesis were normalized by cell viability for each sample of the experimental and control groups.

\section{EGF and VEGF synthesis}

Results also demonstrated that EGF synthesis by epithelial cells was decreased for ZA-treated cells at $24 \mathrm{~h}$, while at $48 \mathrm{~h}$, a negative effect on this synthesis was observed for SA at 1 and $5 \mu \mathrm{M}$ and for ZA at all concentrations (Fig. 6a, b).

VEGF synthesis by gingival fibroblasts was increased by SA at $5 \mu \mathrm{M}$ for the 24-h period, while ZA did not significantly affect this synthesis (Fig. 6c). At 48 h, as observed for the former period, VEGF synthesis was positively affected by SA, while cells treated with ZA showed results similar to those for the control group (Fig. 6d). Results of EGF and VEFG synthesis were normalized by cell viability for each sample of the experimental and control groups.

\section{Synthesis of IgG}

Evaluation of the synthesis of immunoglobulin $\mathrm{G}$ by epithelial cells demonstrated that the exposure to both types of bisphosphonates at all concentrations resulted in significant increases of this synthesis when compared with that of the control group, with no difference among treated groups (Fig. 7). IgG concentration of each sample was normalized by the corresponding cell viability rate.

\section{Discussion}

Several studies have demonstrated that bisphosphonates are associated with the development of oral osteonecrosis (15, 16). This effect seems to be related to a direct toxicity of these
Fig. 3 Number of epithelial cells adhered to the titanium surface after treatment with

bisphosphonates for $24 \mathrm{~h} \mathrm{(a)}$ and $48 \mathrm{~h}$ (b) and number of gingival fibroblasts adhered to the titanium discs after treatment with bisphosphonates for 24 (c) and $48 \mathrm{~h}$ (d). Bars represent medium and standard deviation; groups identified by different symbols indicate statistical difference (Mann-Whitney, $p<0.05$ ) a

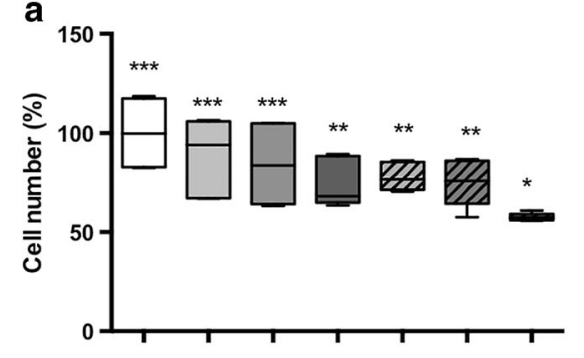

b

C

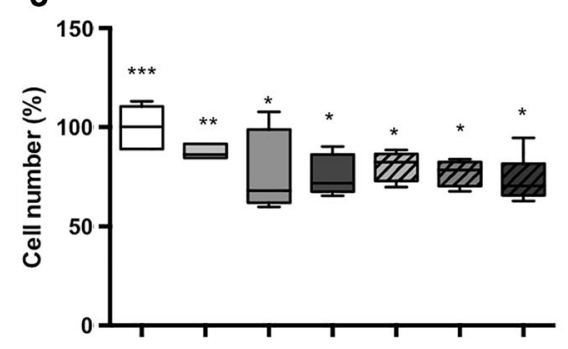

d
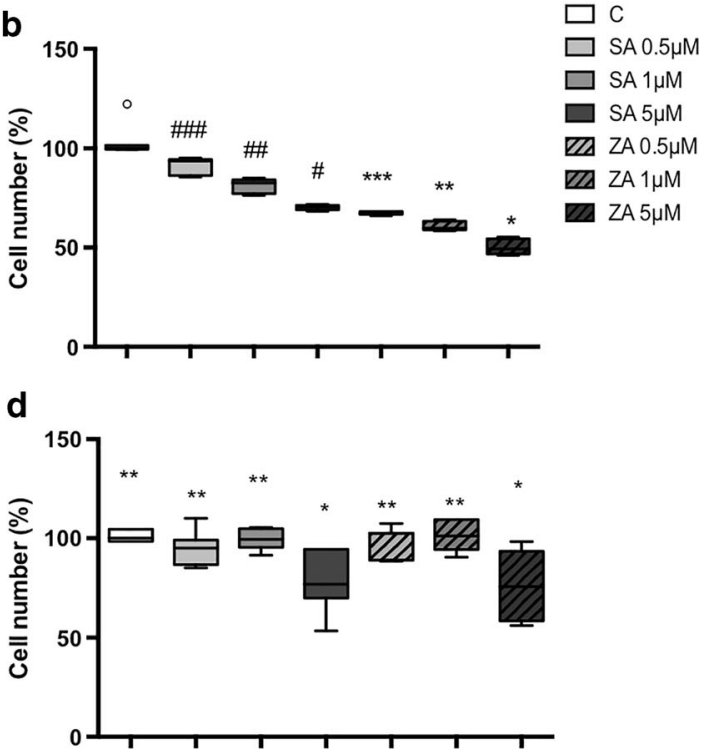
Fig. 4 Viability of epithelial cells adhered to the titanium surface after treatment with

bisphosphonates for $24 \mathrm{~h}$ (a) and $48 \mathrm{~h}$ (b) and viability of gingival fibroblasts adhered to the titanium surface after treatment with bisphosphonates for $24 \mathrm{~h} \mathrm{(c)} \mathrm{and}$ $48 \mathrm{~h}$ (d). Bars represent medium and standard deviation; groups identified by different symbols indicate statistical difference (Mann-Whitney, $p<0.05$ )
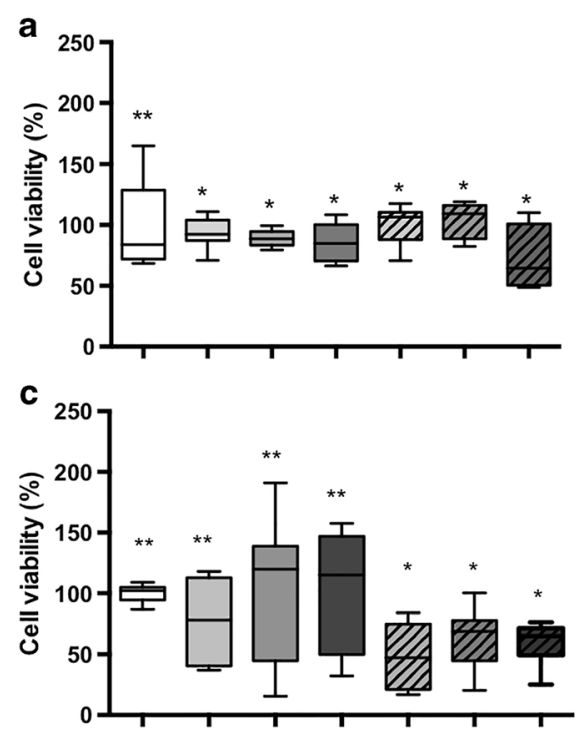
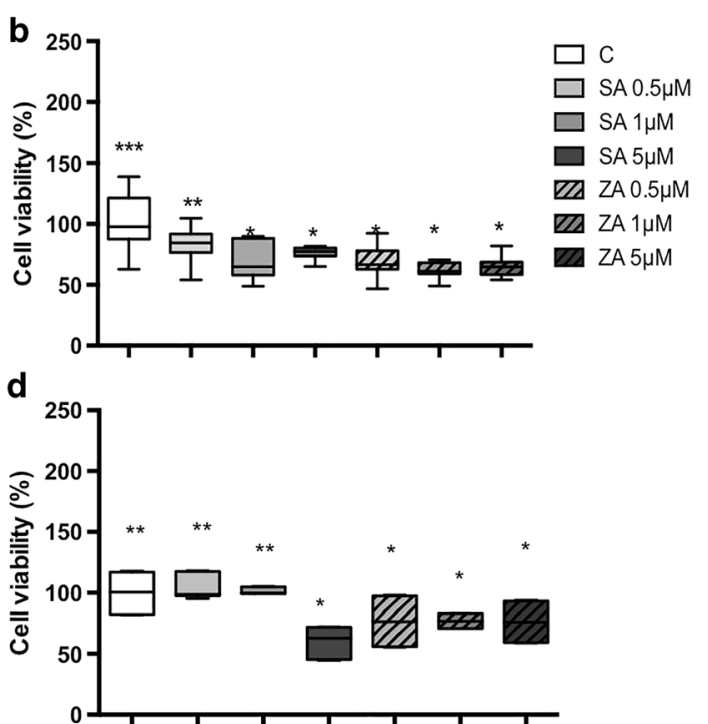

drugs to the bone and oral mucosal cells, as well as to other local factors such as trauma and oral microbiota (7, 15-18). According to clinical studies, the use of bisphosphonates, especially zoledronic acid, has also been related to instances of failure of oral implants, while these failures seem to be significantly lower for patients treated with less potent or orally administered bisphosphonates, such as sodium alendronate (24-26), and these adverse events can occur as a short-term or even as a late effect more than 24 months after implant insertion (19).

The different outcomes for patients undergoing bisphosphonate treatment highlight the hypothesis that these effects might have a direct relationship to the types and regimens of these drugs $(19,27)$.

Bisphosphonates are indicated for the treatment of neoplastic and metabolic bone diseases (28). Over the decades, the evolution of these drugs has resulted in the development of more potent drugs (2). However, along with high potency, the effects of toxicity seem to be higher for these medications (3-6). Bisphosphonates can be prescribed for oral or intravenous intake, according to the type of drug, and can be indicated for different periods and intervals (2). These factors seem to be directly associated with the adverse effects described for the oral cavity $(19,27)$.

Results of this study demonstrated that the type of bisphosphonate is related to the toxicity of these drugs in oral mucosal cells, as is the concentration of bisphosphonate that is in contact with these cells. In a correlation to clinical events, these are the concentrations that can be released from the bone tissue at the time of the insertion of osseointegrated implants. Sodium alendronate has been reported to promote lower toxicity to oral mucosal cells when compared with ZA, and these results have been correlated to the failures of oral implants $(19,27)$.
Fig. 5 Collagen synthesis by epithelial cells seeded on titanium surface after treatment with bisphosphonates for $24 \mathrm{~h} \mathrm{(a)} \mathrm{and}$ $48 \mathrm{~h}$ (b) and collagen synthesis by gingival fibroblasts seeded on titanium surface after treatment with bisphosphonates for $24 \mathrm{~h}(\mathbf{c})$ and $48 \mathrm{~h}$ (d). Bars represent medium and standard deviation; groups identified by different symbols indicate statistical difference (Mann-Whitney, $p<0.05)$
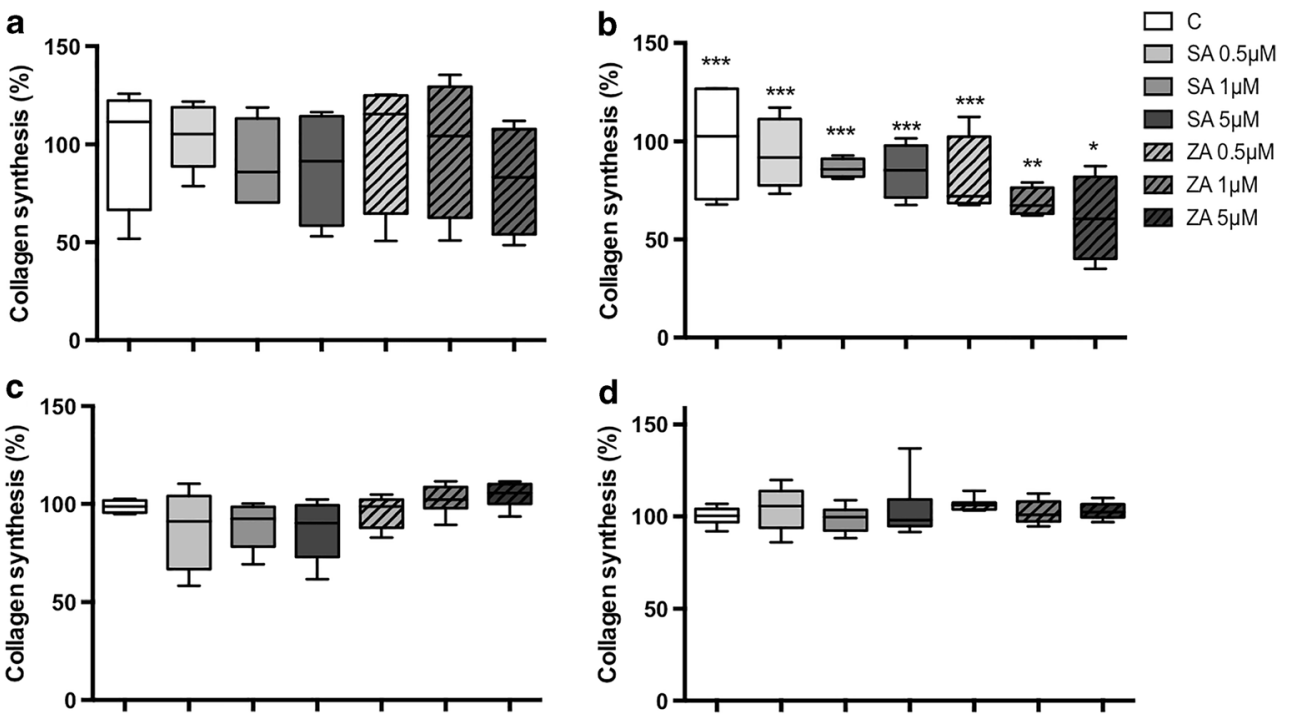
Fig. 6 EGF synthesis by epithelial cells seeded on titanium surface after treatment with bisphosphonates for $24 \mathrm{~h} \mathrm{(a)} \mathrm{and}$ $48 \mathrm{~h}$ (b) and EGF synthesis by epithelial cells seeded on titanium surface after treatment with bisphosphonates for $24 \mathrm{~h}(\mathbf{c})$ and $48 \mathrm{~h}$ (d). Bars represent medium and standard deviation; groups identified by different symbols indicate statistical difference (Mann-Whitney, $p<0.05$ )
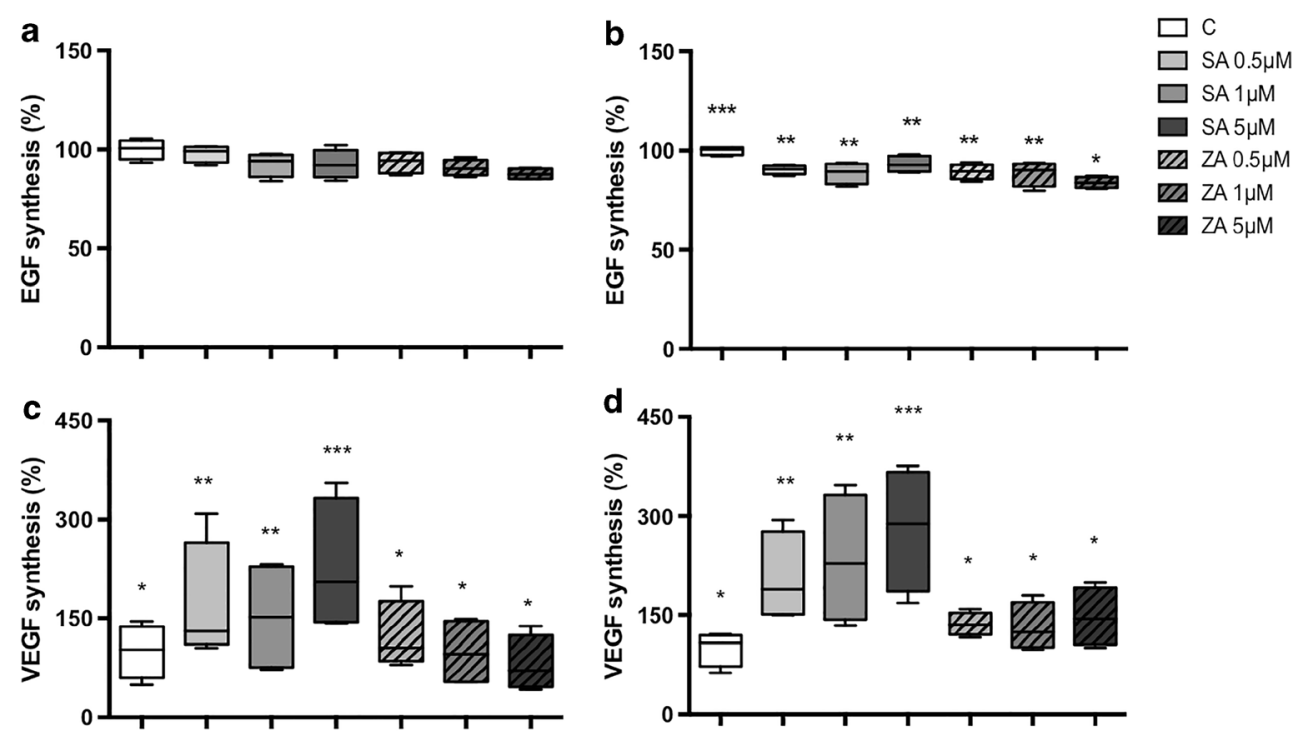

The interface between gingival tissue and the dental surface is formed by the intimate relation of the junctional epithelium and connective tissue to enamel and cementum (29). This interface provides a physical and a biological barrier that protects the periodontal tissues from the invasion of pathogens (29). Therefore, the achievement of an effective biological seal is crucial for the maintenance of implant components and tissue homeostasis.

Several factors can affect the establishment of a biological seal, such as poor adhesion of oral mucosal cells to the prosthetic components (23). After the insertion of oral implants, these cells may adhere to the abutment, and this attachment must be followed by the expression of phenotypic characteristics related to the synthesis of adhesion molecules, in addition to extracellular molecules, growth factors, inflammatory cytokines, and immunoglobulins $(23,29)$.

The first and more evident effect of the presence of bisphosphonates was the lack of adhesion of these cells to the titanium surface. Since the attachment of cells could not be achieved, the physical barrier created by the interaction of gingival tissue and abutments was not effective, thus

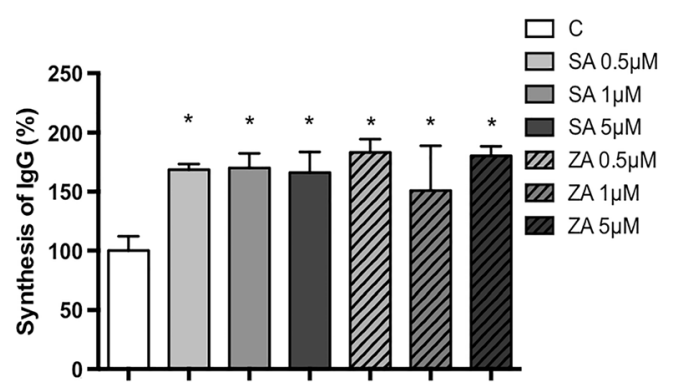

Fig. 7 IgG synthesis by epithelial cells seeded on titanium surface after treatment with bisphosphonates for $48 \mathrm{~h}$. Bars represent medium and standard deviation; groups identified by different symbols indicate statistical difference (Tukey, $p<0.05$ ) jeopardizing the other cell functions responsible for creating a biological barrier and mucosal healing.

Treatment with bisphosphonates negatively affected the cellular functions associated with adhesion of these cells to the titanium surfaces - viability and synthesis of growth factors - mainly when cells were exposed to ZA. However, at high concentrations, SA also caused a disturbance in the adhesion and metabolism of epithelial cells and gingival fibroblasts.

When the synthesis of immunoglobulin G was evaluated, a significant increase in the amount of this protein was detected for both bisphosphonates at all concentrations. This result can be related to an inflammatory response triggered by the presence of these drugs (30). In addition, this effect can also result in increased collagen synthesis, characteristic of inflammatory fibrous conditions (31), which could explain the increased collagen amount observed for bisphosphonate-treated cells.

Taken together, the results of this study illustrate the cellular events that may be involved in the failure of an efficient biological seal to be established when oral mucosal cells are exposed to bisphosphonates, leading to the failure of oral implants. ZA showed more intense effects on these cells, highlighting the importance of a full case-study and evaluation of risks and benefits for the insertion of oral implants in patients under treatment with this drug. Even for patients treated with SA, careful planning should not be dismissed, to avoid the development of osteonecrotic lesions and other adverse effects.

Moreover, these results also highlight the need for new strategies for the improvement of dental care for patients under bisphosphonate treatment, such as the development and improvement of implant components that could provide a better biological environment for cell adhesion, even in the presence of these medications. 
Acknowledgements Authors acknowledge the National Council for Scientific and Technological Development - CNPq (Grants: 157779/ 2015-7, 442637/2014-4, 303599/2014, 307696/2014) for the financial suport.

\section{Compliance with ethical standards}

Conflict of interest The authors declare that they have no conflict of interest.

Funding The work was supported by the National Council for Scientific and Technological Development - CNPq (Grants: 157779/ 2015-7, 442637/2014-4, 303599/2014, 307696/2014).

Ethical approval All procedures were performed in accordance to Ethics Committee of Araraquara School of Dentistry, Unesp, Brazil.

Informed consent Gingival fibroblasts were isolated after patients agreement by signing of informed consent.

\section{References}

1. Rogers MJ, Gordon S, Benford HL et al (2000) Cellular and molecular mechanisms of action of bisphosphonates. Cancer 88:29612978

2. Russell RG (2011) Bisphosphonates: the first 40 years. Bone 49:219

3. Simon MJK, Niehoff P, Kimming B, Açil Y (2010) Expression profile and synthesis of different collagen types I, II, III and V of human gingiva fibroblasts, osteoblasts, and SaOS-2 cells after bisphosphonate treatment. Clin Oral Invest 14:51-58

4. Walter C, Klein MO, Pabst A, Al-Nawas B, Duschner H, Ziebart T (2010) Influence of bisphosphonates on endothelial cells, fibroblasts, and osteogenic cells. Clin Oral Invest 14:35-41

5. Basso FG, Pansani TN, Oliveira CF et al (2013) Cytotoxic effects of zoledronic acid on human epithelial cells and gingival fibroblasts. Braz Dent J 24:551-558

6. Basso FG, Turrioni APS, Hebling J, de Souza Costa CA (2013) Zoledronic acid inhibits human osteoblast activities. Gerontology 59:534-541

7. Migliorati CA, Casiglia J, Epstein J, Jacobsen PL, Siegel MA, Woo S (2005) Managing the care of patients with bisphosphonateassociated osteonecrosis. JADA 136:1658-1668

8. Woo S, Hellstein JW, Kalmar JR (2006) Systematic review: bisphosphonates and osteonecrosis of the jaws. Ann Intern Med 144:753-761

9. Diel IJ, Fogelman I, Al-Nawas B et al (2007) Pathophysiology, risk factors and management of bisphosphonate-associated osteonecrosis of the jaw: is there a diverse relationship of amino and non-aminobisphosphonates? Crit Rev Oncol Hematol 64:198207

10. Idris AI, Rojas J, Greis IR, van't Hof RJ, Ralston SH (2008) Aminobisphosphonates cause osteoblast apoptosis and inhibit bone nodule formation in vitro. Calcif Tissue Int 82:191-201

11. Orriss IR, Key ML, Colston KW, Arnett TR (2008) Inhibition of osteoblast function in vitro by aminobisphosphonates. J Cell Biochem 106:109-118

12. Scheper MA, Badros A, Salama AR et al (2009) A novel bioassay model to determine clinically significant bisphosphonate levels. Support Care Cancer 17:1553-1557
13. Ravosa MJ, Ning J, Liu Y, Stack S (2011) Bisphosphonate effects on the behavior of oral epithelial cells and oral fibroblasts. Arch Oral Biol 56:491-498

14. Basso FG, Turrioni APS, Soares DG, Bagnato VS, Hebling J, de Souza Costa CA (2014) Low-level laser therapy for osteonecrotic lesions: effects on osteoblasts treated with zoledronic acid. Support Care Cancer 22:2741-2748

15. Migliorati CA, Woo S, Hewson I et al (2009) A systematic review of bisphosphonate osteonecroses (BON) in cancer. Support Care Cancer 18:1099-1106

16. Landesberg R, Woo V, Cremers S et al (2011) Potential pathophysiological mechanism in osteonecroses of the jaw. Ann N Y Acad Sci 1218:62-69

17. Reid IR (2009) Osteonecrosis of the jaw-who gets it and why? Bone 44:4-10

18. Otto S, Pautke C, Opelz C et al (2010) Osteonecrosis of the jaw: effect of bisphosphonate type, local concentration, and acidic milieu on the pathomechanism. J Oral Maxillofac Surg 68:2837-2845

19. Madrid C, Sanz M (2009) What impact do systemically administered bisphosphonates have on oral implant therapy? A systematic review. Clin Oral Impl Res 20:87-95

20. Javed F, Almas K (2010) Osseointegration of dental implants in patients undergoing bisphosphonate treatment: a literature review. J Periodontol 81:479-484

21. Chadha G, Ahmadieh A, Kumar S, Sedghzadeh PP (2013) Osseointegration of dental implants and osteonecrosis of the jaw in patients treated with bisphosphonate therapy: a systematic review. J Oral Implantol 39:510-520

22. Taxel P, Ortiz D, Shafer D et al (2014) The relationship between implant stability and bone health markers in post-menopausal women with bisphosphonate exposure. Clin Oral Invest 18:49-57

23. An N, Rausch-fan X, Wieland M, Matejka M, Andrukhov O, Schedle A (2012) Initial attachment, subsequent cell proliferation/ viability and gene expression of epithelial cells related to attachment and wound healing in response to different titanium surfaces. Dent Mater 28:1207-1214

24. Etminan M, Aminzadeh K, Mathew IR, Brophy JM (2008) Use of oral bisphosphonates and risk of aseptic osteonecrosis: a nested case-control study. J Rheumatol 35:691-695

25. Khan AA, Sándor GK, Dore E et al (2008) Canadian consensus practice guidelines for bisphosphonate associated osteonecrosis of the jaw. J Rheumatol 35:1391-1397

26. Bedogni A, Bettini G, Totola A, Saia G, Nocini PF (2010) Oral bisphosphonate-associated osteonecrosis of the jaw after implant surgey: a case report and literature review. J Oral Maxillofac Surg 68:1662-1666

27. Assael LA (2009) Oral bisphosphonates as a cause of bisphosphonate-related osteonecrosis of the jaws: clinical findings, assessment of risks, and preventive strategies. J Oral Maxillofac Surg 67:35-43

28. Body JJ, Mancini I (2002) Bisphosphonates for cancer patients: why, how, and when? Support Care Cancer 10:399-407

29. Hynes RO (1992) Integrins: versatility, modulation and signaling in cell adhesion. Cell 69:11-25

30. Patidar K, Parwani RN, Wanjari SP (2011) Correlation of salivary and serum $\operatorname{IgG}$, IgA levels wih total protein in oral submucous fibrosis. J Oral Sci 53:97-102

31. Tilakaratne WM, Klinikowki MF, Saku T, Peters TJ, Warnakulasuriya S (2006) Oral submucous fibrosis: review on aetiology and pathogenesis. Oral Oncol 42:561-568 